\title{
Effects of the Full Coverage Policy of Essential Medicines on Inequality in Medication Adherence: A Longitudinal Study in Taizhou, China
}

\section{Zhigang Guo}

Department of Pharmacy, Peking University School and Hospital of Stomatology

\section{Liguang Zheng}

Department of Pharmacy, Peking University School and Hospital of Stomatology

\section{Mengyuan Fu}

School of Pharmaceutical Sciences, Peking University

Huangqianyu Li

International Research Center for Medicinal Administration, Peking University

\section{Lin Bai}

School of Pharmaceutical Sciences, Peking University

Xiaodong Guan ( $\square$ guanxiaodong@pku.edu.cn )

School of Pharmaceutical Sciences, Peking University

\section{Luwen Shi}

School of Pharmaceutical Sciences, Peking University

\section{Research Article}

Keywords: Full coverage policy, Free, Essential medicines, Inequality in medication adherence, Concentration index, China

Posted Date: September 1st, 2021

DOI: https://doi.org/10.21203/rs.3.rs-641702/v2

License: (c) (1) This work is licensed under a Creative Commons Attribution 4.0 International License. Read Full License

Version of Record: A version of this preprint was published at Frontiers in Pharmacology on February 3rd, 2022. See the published version at https://doi.org/10.3389/fphar.2022.802219. 


\title{
Effects of the Full Coverage Policy of Essential Medicines on inequality in medication adherence: a longitudinal study in Taizhou, China
}

Zhigang Guo ${ }^{1,2}$, Liguang Zheng ${ }^{1}$, Mengyuan $\mathrm{Fu}^{3}$, Huangqianyu $\mathrm{Li}^{2}$, Lin $\mathrm{Bai}^{3}$, Xiaodong Guan ${ }^{2,3 *}$, Luwen $\mathrm{Shi}^{2,3}$

* Correspondence: guanxiaodong@pku.edu.cn

1 Department of Pharmacy, Peking University School and Hospital of Stomatology, Beijing 100081, China

2 International Research Center for Medicinal Administration, Peking University, Beijing 100191, China

3 School of Pharmaceutical Sciences, Peking University, Beijing 100191, China

\begin{abstract}
Background: The full coverage policy for essential medicines (FCPEMs) was proposed and implemented in Taizhou city of Zhejiang Province of China to promote equal access and adherence to medicines. This study aimed to examine the effects of FCPEMs on the inequality in medication adherence among local patients with hypertension and diabetes, and to explore their influencing factors

Methods: We collected electronic health records of patients with hypertension and diabetes of three districts of Taizhou from 2011-2016. With the implementation time of FCPEMs being different, we applied a retrospective longitudinal study design and selected the records of 1 baseline year before and 3 follow-up years after following the implementation of FCPEMs. All data entries of the same patient were aggregated and generated a dataset with 4-year longitudinal data. The concentration index (CI) and its decomposition method were employed to measure the factors contributing to inequality in medication adherence and the role played by FCPEMs.
\end{abstract}

Results: The sample size of the 4 years retrospective longitudinal data rose from 264,836 to $315,677,340,512$ and 355,676 individuals and the proportion of the patient taking the free medicines were $17.6 \%$ to $25.0 \%$ and $29.8 \%$ after FCPEMs. The proportion of patients with high adherence increased from $39.9 \%$ to $51.6 \%, 57.2 \%$, $60.5 \%$ and CI changed from 0.073 to $-0.011,-0.029,-0.035$, where the rate of the contribution of FCPEMs were $54.792 \%, 1.223 \%$ and $-19.092 \%$ and ranked 2 nd, 7 th and 2nd after the implementation of FCPEMs. The changes in CI of medication adherence for every two years were $-0.084,-0.018,-0.006$, and the contribution of FCPEMs were $-0.006,0.006,0.007$, ranking the 2nd, 2nd and 1 st and mainly attributed to the changes of CI of FCPEMs.

Conclusions: The medication adherence of patients with hypertension and diabetes improved after the implementation FCPEMs in Taizhou, but the inequality did not show a consistent rate of improvement. In general, FCPEMs contributed to improvements in the inequality in medication adherence. FCPEMs could be a protective factor against the income-related inequalities, but this would need further investigations and to be accompanied by other systematic efforts.

Keywords: Full coverage policy; Free; Essential medicines; Inequality in medication adherence; Concentration index; China 


\section{Background}

Unequal access to medicines is a universal problem for healthcare system reforms [1]. It exacerbates a phenomenon well documented in literature that people from lower-income and minority groups experience higher health risks and are more vulnerable to medication costs [2, 3]. Full coverage policy for medicines (FCPMs) is a policy strategy to promote equal access and adherence to medicines. Depending on specific contexts, FCPMs may also be known as "free", "full reimbursement", or "fee exemption" medicines policy. According to the Pharmaceutical Country Profiles by the World Health Organization, all 105 listed countries had implemented FCPMs to some extent. Among the countries, 54 had full coverage for essential medicines and 56 for chronic diseases [4]. FCPMs is also increasingly studied and implemented in hypertension and diabetes interventions in the United States [5, 6], Canada [7], Brazil [8], Spain [9, 10], Madagascar [11], India [12], and Burkina Faso [13].

China has adopted FCPMs for antihypertensive and hypoglycemic medicines. By the end of 2020, 16 provinces had selected at least one district/county as pilot area(s) to explore various policy strategies to manage hypertension and diabetes [4, 14-16]. In 2011, Taizhou, Zhejiang was among the first cities to implement the full coverage policy for essential medicines (FCPEMs). The policy was set out to be as follows: 1) all nine districts/counties administered by Taizhou city were required to develop a full-coverage medication catalogue between 2012 and 2013, specifying what medicines for hypertension and diabetes listed in the National Essential Medicines List of China (version 2012) would be covered in full. 2) Eligible patients could access to medicines listed in this catalogue without any costs, including drug, prescription and related medical costs, at any primary care or designated facilities. 3) Physicians at primary care and designated facilities were responsible for evaluating selected medicines' clinical benefits and appropriateness for patients, and adjusting the medication plan if clinical outcomes were poor. 4) As one part of the basic public health services, China had been establishing health records and providing free chronic disease management services for every patient with hypertension and diabetes from the new healthcare reform in 2009 [17, 18]. All hypertension and diabetes patients using medicines covered must be enrolled in chronic disease management services and have their medication and disease management plan incorporated into health records.

Studies indicated that FCPMs and FCPEMs could reduce medicine-related costs for patients, improve affordability and accessibility of medicines, and promote medication adherence $[1,4,19]$. It can also help with disease prevention and control [15] and achieve more economical benefits for society [20]. There is emerging evidence that implementation of FCPMs and FCPEMs would favorably benefit vulnerable populations in accessing medications [1, 10, 13, 15], though this is better supported by further investigations. Therefore, we aimed to analyze the change in medication adherence before and after the implementation of FCPEMs in Taizhou, and to explore the policies' effects on inequality.

\section{Methods}

Settings 
Taizhou is a prefecture-level city with a total area of $10050 \mathrm{~km}^{2}$ in Zhejiang Province, locating in the central area of the Yangtze River Delta in China. The city administers three urban districts (Jiaojiang, Huangyan, and Luqiao), three county-level cities (Linhai, Wenling, and Yuhuan) and three counties (Tianhai, Xianju, and Sanmen). In 2016, Taizhou had a population of 5.2 million, 9.1\% of them aged over 65 years and 19.3\% aged 45-64 years. The annual disposable income per capita was 5321.5 dollars. The average number of health professionals, hospital beds, physicians, and nurses for every thousand residents was 6.8, 4.5, 2.8 and 2.7 respectively. [21]

\section{Data source and Design}

We collected electronic health records of patients with hypertension and diabetes from 2011 to 2016, which included patients' demographics (e.g. gender, age, income, level of education, medical insurance and so forth) and regular follow-up data (e.g. medicines prescribed, medication adherence, and health behaviors such as smoking and drinking) [18]. We used a retrospective longitudinal study design to analyze the impact of FCPEMs. The policy was implemented in the nine districts/counties with different schedules. Records collected 12 months prior to the local policy implementation were treated as the baseline data. Records of the 1-12 months, 13-24 months and 25-36 months after local policy implementation were treated in joint as the three-year follow-up data. All records of the same patient in a given year were aggregated, and in this way we generated a set of 4-year retrospective longitudinal data. Due to system upgrading, only data of Huangyan District, Linhai City, and Wenling City were eligible over the study period. Therefore, the analysis of this study was limited to patients residing in these 3 areas. The policy implementation schedule and the medicine catalogue for each area were shown in Appendix 1.

\section{Measures and Determinants}

According to the requirements and regulations of the Chronic Disease Management Services of China [17], family physicians should administer follow-up surveys regularly to monitor disease status. In Taizhou, medication adherence would be assessed in follow-up surveys and be translated into three categories: "regular medication use", "irregular medication use" and "taking no medication". In our analysis, "regular medication use" was treated as high adherence (computed as 1), "irregular medication use" and "taking no medication" were regarded as poor adherence (computed as 0 ).

If the patient had used the medicines covered by FCEMPs in the given year, they would be categorized as FCPEM covered (computed as 1), otherwise as not covered (computed as 0 ).

Based on previous research [22-24], our analysis also included the following categorical variables which might impact medication adherence (See Table 1): gender, age, income group (the low/ middle/ high income group with one third of population by rank of the annual household income), hukou status, residential area, marital status, employment status, educational level, medical insurance, smoking, drinking, and disease type.

\section{Statistical analysis}


The concentration index (CI) and its decomposition recommended by Wagstaff and Van Doorslaer were applied to analyze the inequity of medication adherence and the contribution of the determinant factors $[2,17]$. The calculation formula of CI is

$$
C I=\frac{2}{\mu} \operatorname{cov}\left(y_{i}, r_{i}\right)
$$

where $y_{i}$ denotes medication adherence ( 0 or 1$), \mu$ is the mean of $y_{i}$, and $r_{i}$ is the fractional rank of the individual in the economic distribution. The value of CI ranges from -1 to 1 , while the smaller absolute value represents higher equity. Thus, 0 implies perfect equality. A positive value signifies a pro-rich effect and a negative value signifies pro-poor effects. The model of the decomposition of CI [25] is

$$
C I=\sum_{k}\left(\frac{\gamma_{k} \bar{X}_{k}}{\mu}\right) C I_{K}+\frac{G C I_{\varepsilon}}{\mu}
$$

where $\gamma_{k}, \bar{X}_{k}$ and $C I_{K}$ is the marginal effect, mean and $C I$ of the independent variables. $\frac{G C I_{\varepsilon}}{\mu}$ represents the residual error team. $\left(\frac{\gamma_{k} \bar{X}_{k}}{\mu}\right)$ denotes the elasticity between $C I_{y}$ and $C I_{K}$, and $\left(\frac{\gamma_{k} \bar{X}_{k}}{\mu}\right) C I_{K}$ is the contribution of the determinant factors. So $\left(\frac{\gamma_{k} \bar{X}_{k}}{\mu}\right) C I_{K} / C I_{y}$ is the rate of contribution.

In order to understand the effect of FCPEMs on medication adherence, the Oaxaca-type decomposition [26] is applied and the equation is

$$
\begin{gathered}
C I_{y(t)}-C I_{y(t-1)}=\sum_{k} \eta_{x(t)}\left(C I_{x(t)}-C I_{x(t-1)}\right)+\sum_{k} C I_{x(t-1)}\left(\eta_{x(t)}-\eta_{x(t-1)}\right)+ \\
\Delta\left(\frac{G C I_{\varepsilon}}{\mu_{t}}\right)=\sum_{k} \eta_{x(t)} \Delta C I_{x}+ \\
\sum_{k} C I_{x(t-1)} \Delta \eta_{x}+\Delta\left(\frac{G C I_{\varepsilon}}{\mu_{t}}\right)
\end{gathered}
$$

where $\eta$ is the elasticity and calculated as $\left(\frac{\gamma_{k} \bar{x}_{k}}{\mu}\right)$. The $\eta_{x(t)} \Delta C I_{x}$ represents the changes of the socioeconomic inequality in determinant factors and $C I_{x(t-1)} \Delta \eta_{x}$ measures the changes of sensitivity between $C I_{y}$ and $C I_{K}$.

All statistical analyses were performed using the STATA software version 14.0.

\section{Results}

\section{Summary statistics}

Table 1 shows the characteristics of the study population from baseline to three years after the implementation of FCPEMs. The sample size of the 4 years retrospective longitudinal data rose from 264,836 to $315,677,340,512$ and 355,676 patients, of which $81.5 \%, 80.4 \%, 79.7 \%$, and $78.7 \%$ were patients with hypertension, respectively. Over the study period, the proportion of patients with high adherence increased from $39.9 \%$ to $51.6 \%, 57.2 \%, 60.5 \%$. The proportion patients taking the free medicines also increased with time, from $17.6 \%$ to $25.0 \%$ and $29.8 \%$ after the FCPEMs.

\section{Table 1 Characteristics of Study Population of the four years}




\begin{tabular}{|c|c|c|c|c|c|}
\hline Variables & Description & $\begin{array}{l}\text { Baseline } \\
(n=264836)\end{array}$ & $\begin{array}{l}\text { First year } \\
(n=315677)\end{array}$ & $\begin{array}{l}\text { Second year } \\
(n=340512)\end{array}$ & $\begin{array}{l}\text { Third year } \\
(\mathrm{n}=355676)\end{array}$ \\
\hline \multirow[t]{2}{*}{ Dependent variable } & High adherence, $\%$ & 39.9 & 51.6 & 57.2 & 60.5 \\
\hline & Poor adherence, $\%$ & 60.1 & 48.4 & 42.8 & 39.5 \\
\hline \multirow[t]{2}{*}{ Policy } & FCPEMs covered, $\%$ & - & 17.6 & 25.0 & 29.8 \\
\hline & Not covered, \% & - & 82.4 & 75.0 & 70.2 \\
\hline \multirow[t]{2}{*}{ Gender } & Female, $\%$ & 61.1 & 60.0 & 59.6 & 60.3 \\
\hline & Male, $\%$ & 38.9 & 40.0 & 40.4 & 40.7 \\
\hline \multirow[t]{2}{*}{ Age } & $0-64, \%$ & 50.0 & 50.1 & 48.8 & 47.1 \\
\hline & $65+, \%$ & 50.0 & 49.9 & 51.2 & 52.9 \\
\hline \multirow[t]{3}{*}{ Income group } & Low, $\%$ & 33.3 & 33.3 & 33.3 & 33.3 \\
\hline & Middle, $\%$ & 33.3 & 33.3 & 33.3 & 33.3 \\
\hline & High, \% & 33.3 & 33.3 & 33.3 & 33.3 \\
\hline \multirow[t]{2}{*}{ Hukou } & Non-agricultural, $\%$ & 2.3 & 2.6 & 2.9 & 2.9 \\
\hline & Agricultural, \% & 97.7 & 97.4 & 97.1 & 97.1 \\
\hline \multirow[t]{2}{*}{ Residential terrain } & Plain area, $\%$ & 72.9 & 73.1 & 73.7 & 74.2 \\
\hline & Mountainous area, $\%$ & 27.1 & 26.9 & 26.2 & 25.8 \\
\hline \multirow[t]{2}{*}{ Marital status } & Unmarried, \%* & 18.0 & 16.9 & 16.2 & 15.6 \\
\hline & Married, $\% * *$ & 82.0 & 83.1 & 83.8 & 84.4 \\
\hline \multirow[t]{2}{*}{ Employment status } & Employed, \% & 13.2 & 13.7 & 14.0 & 14.2 \\
\hline & Unemployed, \% & 86.8 & 86.3 & 86.0 & 85.8 \\
\hline \multirow[t]{4}{*}{ Educational level } & $\begin{array}{l}\text { Illiterate and } \\
\text { semiliterate, \% }\end{array}$ & 40.6 & 38.4 & 36.9 & 35.6 \\
\hline & Primary school, \% & 42.3 & 42.4 & 42.9 & 43.3 \\
\hline & Junior middle school, $\%$ & 14.5 & 16.0 & 16.8 & 17.7 \\
\hline & $\begin{array}{l}\text { High school and } \\
\text { above, \% }\end{array}$ & 2.6 & 3.2 & 3.4 & 3.5 \\
\hline \multirow[t]{3}{*}{ Medical insurance } & None, $\%$ & 4.9 & 5.1 & 5.1 & 5.3 \\
\hline & URRBMI, \%*** & 92.0 & 91.4 & 91.1 & 90.5 \\
\hline & UEBMI and CMI, \%**** & 3.1 & 3.5 & 3.8 & 4.1 \\
\hline \multirow[t]{2}{*}{ Smoke } & No, $\%$ & 85.3 & 84.5 & 84.9 & 84.4 \\
\hline & Yes, $\%$ & 14.7 & 15.5 & 15.1 & 15.6 \\
\hline \multirow[t]{2}{*}{ Drink } & No, $\%$ & 92.8 & 92.3 & 92.3 & 91.2 \\
\hline & Yes, $\%$ & 7.2 & 7.7 & 7.7 & 8.8 \\
\hline \multirow[t]{2}{*}{ Disease } & Hypertension, $\%$ & 81.5 & 80.4 & 79.7 & 78.7 \\
\hline & Diabetes, $\%$ & 18.5 & 19.6 & 20.3 & 21.3 \\
\hline
\end{tabular}

Note: * including married and remarried

** including unmarried, divorced, and widowed

*** Urban Rural Resident Basic Medical Insurance

**** Urban Employee Basic Medical Insurance and Commercial Medical Insurance

\section{Description in medication adherence and its CI}

Table 2 demonstrates changes in medication adherence of patients, stratified by income, and CI of medication adherence over the four years. Patients from all income 
groups experienced varying degrees of improvement in medication adherence. Patients from the low-income group experienced the largest improvement $(33.2 \%$ to $53.0 \%, 61.2,65.4 \%)$, followed by patients from the middle-income group ( $42.6 \%$ to $51.6 \%, 56.6 \%, 59.3 \%)$. Patients from the high-income group experienced the smallest increase in adherence rate, from $44.6 \%$ to $50.2 \%, 53.6 \%$, and $56.5 \%$. CI of medication adherence changed from 0.073 to $-0.011,-0.029,-0.035$, namely from pro-rich bias to pro-poor bias before and after FCPEMs and the inequality worsened.

Table 2 Medication adherence and CI of the four years

\begin{tabular}{lllll}
\hline Medication adherence & $\begin{array}{l}\text { Baseline } \\
(\mathbf{n = 2 6 4 8 3 6})\end{array}$ & $\begin{array}{l}\text { First year } \\
(\mathbf{n = 3 1 5 6 7 7})\end{array}$ & $\begin{array}{l}\text { Second year } \\
(\mathbf{n = 3 4 0 5 1 2})\end{array}$ & $\begin{array}{l}\text { Third year } \\
(\mathbf{n = 3 5 5 6 7 6})\end{array}$ \\
\hline $\begin{array}{l}\text { Proportion of high adherence } \\
\quad \text { Low-income group }\end{array}$ & $33.2 \%$ & $53.0 \%$ & $61.2 \%$ & $65.4 \%$ \\
$\quad$ Middle-income group & $42.6 \%$ & $51.6 \%$ & $56.6 \%$ & $59.3 \%$ \\
$\quad$ High-income group & $44.6 \%$ & $50.2 \%$ & $53.6 \%$ & $56.5 \%$ \\
CI & 0.073 & -0.011 & -0.029 & -0.035 \\
\hline
\end{tabular}

\section{Decomposition of inequality in medication adherence}

Table 3 presents the elasticity and the rate of contribution of determinants on CI of medication adherence over the four years. During the follow-up period, the elasticity of the policy increased from 0.103 to $0.131,0.141$, implying that the positive association between CI of policy and medication adherence strengthened overtime. The rate of the contribution of the policy to medication adherence changed from $54.792 \%$ to $1.223 \%$ and $-19.092 \%$ by the end of each follow-up year, respectively. Its ranking dropped from $2^{\text {nd }}$ at the end of the first follow-up year to $7^{\text {th }}$ by the second year and climbed back to $2^{\text {nd }}$ by the end of the follow-up period. Meanwhile, the CI of medication adherence were $-0.011,-0.029$ and -0.035 . That is the impact of FCPEMs was pro-poor inequality at the beginning two years and pro-rich inequality in the third year.

Table 3 Decomposition of CI in medication adherence over the four years

\begin{tabular}{|c|c|c|c|c|c|c|c|c|}
\hline \multirow[t]{2}{*}{ Determinants } & \multicolumn{2}{|c|}{$\begin{array}{c}\text { Baseline } \\
(\mathrm{n}=\mathbf{2 6 4 8 3 6})\end{array}$} & \multicolumn{2}{|c|}{$\begin{array}{l}\text { First year } \\
(n=315677)\end{array}$} & \multicolumn{2}{|c|}{$\begin{array}{c}\text { Second year } \\
(\mathrm{n}=\mathbf{3 4 0 5 1 2})\end{array}$} & \multicolumn{2}{|c|}{$\begin{array}{l}\text { Third year } \\
(\mathrm{n}=355676)\end{array}$} \\
\hline & Elast $^{1}$ & $\mathrm{R}$ of Cont $^{2}$ & Elast $^{1}$ & $\mathrm{R}$ of Cont $^{2}$ & Elast $^{1}$ & $\mathrm{R}$ of Cont ${ }^{2}$ & Elast $^{1}$ & $\mathrm{R}$ of $\mathrm{Cont}^{2}$ \\
\hline \multicolumn{9}{|l|}{ Policy (Ref: Control) } \\
\hline Free medicines & 0.000 & $0.000 \%$ & 0.103 & $54.792 \%$ & 0.131 & $1.223 \%$ & 0.141 & $-19.092 \%$ \\
\hline \multicolumn{9}{|l|}{ Gender (Ref: Female) } \\
\hline Male & -0.012 & $-0.533 \%$ & -0.008 & $2.155 \%$ & -0.008 & $0.731 \%$ & -0.004 & $0.254 \%$ \\
\hline \multicolumn{9}{|l|}{ Age (Ref: 0-64) } \\
\hline $65+$ & 0.046 & $-4.748 \%$ & 0.045 & $28.947 \%$ & 0.038 & $9.038 \%$ & 0.036 & $6.206 \%$ \\
\hline \multicolumn{9}{|l|}{ Income group (Ref: Low) } \\
\hline Middle & 0.068 & $3.319 \%$ & -0.026 & $6.806 \%$ & -0.050 & $4.711 \%$ & -0.055 & $3.161 \%$ \\
\hline High & 0.086 & $75.918 \%$ & -0.030 & $175.906 \%$ & -0.069 & $156.103 \%$ & -0.074 & $139.946 \%$ \\
\hline \multicolumn{9}{|l|}{ Hukou (Ref: Non-agricultural) } \\
\hline Agriculture & -0.156 & $1.735 \%$ & -0.130 & $-10.632 \%$ & -0.201 & $-7.496 \%$ & -0.140 & $-4.359 \%$ \\
\hline Residential terrain (Ref: Plain area) & & & & & & & & \\
\hline
\end{tabular}




\begin{tabular}{|c|c|c|c|c|c|c|c|c|}
\hline Mountainous area & -0.010 & $-0.386 \%$ & -0.020 & $2.863 \%$ & -0.020 & $0.588 \%$ & -0.023 & $0.564 \%$ \\
\hline \multicolumn{9}{|c|}{ Marital status (Ref: Unmarried) } \\
\hline Married & -0.005 & $-0.144 \%$ & 0.010 & $-1.842 \%$ & 0.011 & $-0.738 \%$ & 0.000 & $0.002 \%$ \\
\hline \multicolumn{9}{|c|}{ Employment status (Ref: Employed) } \\
\hline Unemployed & -0.021 & $1.119 \%$ & -0.128 & $-44.608 \%$ & -0.124 & $-16.909 \%$ & -0.086 & $-9.640 \%$ \\
\hline \multicolumn{9}{|c|}{$\begin{array}{l}\text { Educational level (Ref: Illiterate and } \\
\text { semiliterate) }\end{array}$} \\
\hline Primary school & -0.008 & $0.056 \%$ & 0.018 & $-0.140 \%$ & 0.022 & $-0.024 \%$ & 0.023 & $-0.137 \%$ \\
\hline Junior middle school & -0.002 & $-0.024 \%$ & 0.011 & $0.711 \%$ & 0.013 & $0.386 \%$ & 0.013 & $0.691 \%$ \\
\hline High school and above & 0.001 & $-0.096 \%$ & 0.003 & $2.301 \%$ & 0.003 & $0.796 \%$ & 0.003 & $0.635 \%$ \\
\hline \multicolumn{9}{|c|}{ Medical insurance (Ref: None) } \\
\hline URRBMI & -0.084 & $0.596 \%$ & -0.098 & $-2.160 \%$ & -0.040 & $-0.479 \%$ & -0.031 & $-0.363 \%$ \\
\hline UEBMI and CMI & 0.002 & $-0.013 \%$ & 0.000 & $0.023 \%$ & 0.005 & $0.089 \%$ & 0.006 & $0.389 \%$ \\
\hline \multicolumn{9}{|l|}{ Smoke (Ref: No) } \\
\hline Yes & -0.013 & $0.949 \%$ & -0.012 & $-4.142 \%$ & -0.012 & $-0.725 \%$ & -0.012 & $-0.622 \%$ \\
\hline \multicolumn{9}{|l|}{ Drink (Ref: No) } \\
\hline Yes & 0.002 & $0.065 \%$ & -0.001 & $-0.128 \%$ & -0.005 & $-0.156 \%$ & -0.004 & $-0.249 \%$ \\
\hline \multicolumn{9}{|l|}{ Disease (Ref: Hypertension) } \\
\hline Diabetes & -0.082 & $-1.060 \%$ & -0.100 & $-4.332 \%$ & -0.109 & $-0.275 \%$ & -0.108 & $0.001 \%$ \\
\hline
\end{tabular}

Note: Elast ${ }^{1}$ : Elasticity; R of Cont ${ }^{2}$ : The Rate of Contribution

\section{Change in the decomposition of $\mathrm{CI}$ in medication adherence}

Table 4 presents the contribution of all determinants in changes medication adherence every two years, with Oaxaca-type decomposition. The change value of CI in medication adherence was $-0.084,-0.018,-0.006$ every two years from baseline to three years after FCPEMs, of which the contribution of the policy was -0.0061 , $0.0057,0.0070$ and ranked in the $2^{\text {nd }}, 2^{\text {nd }}$ and $1^{\text {st }}$ place. From the results of Oaxaca-type decomposition, the contribution of the policy was mainly attributable to the changes of CI of FCPEMs $(-0.0061,0.0074,0.0070)$ and experienced a minor impact by the changes of sensitivity $(0.0000,-0.0017,0.0000)$.

Table 4 Oaxaca decomposition of CI in medication adherence over the four years

\begin{tabular}{|c|c|c|c|c|c|c|c|c|c|}
\hline \multirow[t]{2}{*}{ Determinants } & \multicolumn{3}{|c|}{ Baseline-First year } & \multicolumn{3}{|c|}{ First-Second year } & \multicolumn{3}{|c|}{ Second-Third year } \\
\hline & $\eta \Delta \mathrm{CI}^{1}$ & CI $\Delta \eta^{2}$ & $\Delta$ Cont $^{3}$ & $\eta \Delta \mathrm{CI}^{1}$ & CI $\Delta \eta^{2}$ & $\Delta$ Cont $^{3}$ & $\eta \Delta \mathrm{CI}^{1}$ & CI $\Delta \eta^{2}$ & $\Delta$ Cont $^{3}$ \\
\hline \multicolumn{10}{|c|}{ Policy (Ref: Control) } \\
\hline Free medicines & -0.0061 & 0.0000 & -0.0061 & 0.0074 & -0.0017 & 0.0057 & 0.0070 & 0.0000 & 0.0070 \\
\hline \multicolumn{10}{|c|}{ Gender (Ref: Female) } \\
\hline Male & 0.0000 & 0.0001 & 0.0002 & 0.0000 & 0.0000 & 0.0000 & 0.0000 & 0.0001 & 0.0001 \\
\hline \multicolumn{10}{|l|}{ Age (Ref: 0-64) } \\
\hline $65+$ & 0.0002 & 0.0001 & 0.0003 & 0.0001 & 0.0005 & 0.0006 & 0.0003 & 0.0002 & 0.0004 \\
\hline \multicolumn{10}{|c|}{ Income group (Ref: Low) } \\
\hline Middle & 0.0002 & -0.0034 & -0.0032 & 0.0001 & -0.0007 & -0.0006 & 0.0004 & -0.0001 & 0.0003 \\
\hline High & -0.0001 & -0.0749 & -0.0750 & -0.0001 & -0.0254 & -0.0255 & -0.0003 & -0.0034 & -0.0037 \\
\hline \multicolumn{10}{|c|}{ Hukou (Ref: Non-agricultural) } \\
\hline Agriculture & 0.0001 & -0.0002 & -0.0001 & 0.0003 & 0.0006 & 0.0010 & 0.0000 & -0.0007 & -0.0006 \\
\hline
\end{tabular}




\begin{tabular}{|c|c|c|c|c|c|c|c|c|c|}
\hline \multicolumn{10}{|c|}{ Residential terrain (Ref: Plain area) } \\
\hline Mountainous area & 0.0002 & -0.0003 & 0.0000 & 0.0002 & 0.0000 & 0.0001 & 0.0000 & 0.0000 & 0.0000 \\
\hline \multicolumn{10}{|c|}{ Marital status (Ref: Unmarried) } \\
\hline Married & 0.0000 & 0.0003 & 0.0003 & 0.0000 & 0.0000 & 0.0000 & 0.0000 & -0.0002 & -0.0002 \\
\hline \multicolumn{10}{|c|}{ Employment status (Ref: Employed) } \\
\hline Unemployed & -0.0001 & 0.0042 & 0.0041 & 0.0001 & -0.0002 & -0.0001 & 0.0000 & -0.0015 & -0.0015 \\
\hline \multicolumn{10}{|c|}{$\begin{array}{l}\text { Educational level (Ref: Illiterate and } \\
\text { semiliterate) }\end{array}$} \\
\hline Primary school & 0.0001 & -0.0001 & 0.0000 & 0.0000 & 0.0000 & 0.0000 & 0.0000 & 0.0000 & 0.0000 \\
\hline Junior middle school & -0.0002 & 0.0001 & -0.0001 & 0.0000 & 0.0000 & 0.0000 & -0.0001 & 0.0000 & -0.0001 \\
\hline High school and above & -0.0001 & -0.0001 & -0.0002 & 0.0001 & 0.0000 & 0.0000 & 0.0000 & 0.0000 & 0.0000 \\
\hline \multicolumn{10}{|c|}{ Medical insurance (Ref: None) } \\
\hline URRBMI & -0.0003 & 0.0001 & -0.0002 & 0.0000 & -0.0001 & -0.0001 & 0.0000 & 0.0000 & 0.0000 \\
\hline UEBMI and CMI & 0.0000 & 0.0000 & 0.0000 & 0.0001 & -0.0002 & 0.0000 & -0.0001 & 0.0000 & -0.0001 \\
\hline \multicolumn{10}{|l|}{ Smoke (Ref: No) } \\
\hline Yes & -0.0002 & -0.0001 & -0.0002 & -0.0003 & 0.0000 & -0.0002 & 0.0000 & 0.0000 & 0.0000 \\
\hline \multicolumn{10}{|l|}{ Drink (Ref: No) } \\
\hline Yes & 0.0000 & -0.0001 & 0.0000 & 0.0000 & 0.0001 & 0.0000 & 0.0000 & 0.0000 & 0.0000 \\
\hline \multicolumn{10}{|l|}{ Disease (Ref: Hypertension) } \\
\hline Diabetes & 0.0014 & -0.0002 & 0.0013 & -0.0004 & 0.0000 & -0.0004 & -0.0001 & 0.0000 & -0.0001 \\
\hline
\end{tabular}

Note: $\eta \Delta \mathrm{CI}: \eta_{\mathrm{x}(\mathrm{t})} \Delta \mathrm{CI}_{\mathrm{x}}=\eta_{\mathrm{x}(\mathrm{t})}\left(\mathrm{CI}_{\mathrm{x}(\mathrm{t})}-\mathrm{CI}_{\mathrm{x}(\mathrm{t}-1)}\right) ; \mathrm{CI} \Delta \eta: \mathrm{CI}_{\mathrm{x}(\mathrm{t}-1)} \Delta \eta_{\mathrm{x}}=\mathrm{CI}_{\mathrm{x}(\mathrm{t}-1)}\left(\eta_{\mathrm{x}(\mathrm{t})}-\eta_{\mathrm{x}(\mathrm{t}-1)}\right)$; $\Delta$ Cont: $\eta \Delta \mathrm{CI}+\mathrm{CI} \Delta \eta=\eta_{\mathrm{x}(\mathrm{t})} \mathrm{CI}_{\mathrm{x}(\mathrm{t})}-\eta_{\mathrm{x}(\mathrm{t}-1)} \mathrm{CI}_{\mathrm{x}(\mathrm{t}-1)}$

\section{Discussion}

This study examined income-related inequalities in medicine adherence using a retrospective longitudinal study design and a sample of patients with hypertension and diabetes in Taizhou of China. We identified that FCPEMs favorably promoted medication adherence among patients from the low-income group as compared with patients from other income groups.

Our study results are consistent with similar studies in that medication adherence among patients improved after the implementation FCPEMs, and that the largest improvement was observed in low-income population. With increasing proportion of patients taking covered medicines year by year, the medication adherence of the general population improved. In other studies on FCPMs, low-income patients who converted from poor to high medication adherence contributed to an increase of $7.8 \%$ in medication adherence to statins [10] and increased twice more than the high-income patients with diabetes [5].

Though the inequality in medicine adherence did not keep continuous improvement, FCPEMs was positive in improving the inequality. From the baseline to the followed three years, the inequality of medication adherence improved in the first two years, but exacerbated in the latter two years. In the process, the contribution of FCPEMs balanced and mitigated the changes of inequality, namely positive in improving the inequality. As two studies showing, FCPMs for cardiovascular disease and cancer reduced the racial and ethnic disparities in medicines between white and 
non-white patients after myocardial infarctions [27, 28]. For the exacerbated inequality, income group (high) was still the greatest barrier to realize equality, while FCPEMs became a positive element against it. As many studies suggesting, medication non-adherence is significantly associated with low-income [29, 30]. Our study shows that FCPEMs could be a protecting factor against this inequality in medication adherence experienced by low-income patients with hypertension and diabetes. This echoes a Targeted Poverty Alleviation program in China demonstrating that FCPMs could protect low-income patients against heavy burden of medicine costs [16].

However, due to the comprehensive impact of various factors, FCPEMs not always produce a pro-poor bias. In our study, we knew changes from CI of FCPEMs worked the main effects, suggesting that the proportion of patients taking free medicines of different groups was the key to transform the inequality. However, factors contributing to uptakes of free medicines varied. One study showed that lower medication adherence among patients from high-income groups could result from mismatch of free medicines with their health needs [22]. Another study showed that age was a promoting factor for uptake of free medicines, with $40 \%$ of the older adults used free medicines to ameliorate their burden of medicine costs [31]. In this study, we found uptake of free medicines might be positively associated with an increase in free medicines covered by the catalogue (see Appendix 1). We can reasonably conclude that the more health needs medicines covered by FCPMs could meet, the more likely FCPMs changed the inequality. The geographical accessibility of designated health facilities [32], qualification of health professionals and pharmacists at these facilities [33, 34], and supports from families and social network [31, 35] were also the factors that could not be ignored.

It is also worth noting that long-term longitudinal data is necessary for evaluating the inequality in medication adherence and revising the FCPMs programs accordingly. If we only used one year data in this study after FCPEMs, the results and conclusions would be different or opposite. Meanwhile, medication adherence is influenced by many factors, thus it would need the comprehensive reform to improve inequality [1, 36]. During the reform, long-term longitudinal data was importance to exhibition the dynamic results [33] and adjust precisely the intervention, such as the FCPEMs and FCPMs. All these highlighted the value of 4 years data of the study.

Nevertheless, our study has several limitations. The prevalence of hypertension and diabetes among residents registered in the local EMR database were $11.2 \%$ and $3.2 \%$ respectively in 2016, which were lower than the disease prevalence shown by epidemiological data [37-39]. This implies a participant bias and that our sample may not be fully representative of the general population residing in Taizhou. Moreover, our measurement of the medication adherence is subject to recall bias and administration bias as health records and follow-up surveys were collected by medical staffs, who might have varying degrees of training in administering surveys. Then, how to optimize the medicines catalogue to meet the health needs of local patients while maintaining economical sustainability awaits further investigations. 


\section{Conclusion}

In conclusion, overall medication adherence of the study population improved after the implementation of FCPEMs in Taizhou, where low-income population experienced the largest increase in adherence to medicines. FCPEMs generally contributed to improving the inequality, though it might not always produce a pro-poor bias. The bias depended on the proportion of patients taking free medicines of different groups, influenced by the interactions among various factors, including the selection of free medicines, the geographical accessibility of designated health facilities, qualification of health professionals and pharmacists at these facilities, and support networks.

\section{Abbreviations}

FCPMs: Full coverage policy for medicines; FCPEMs: Full coverage policy for essential medicines; CI: The concentration index; URRBMI: Urban Rural Resident Basic Medical Insurance; UEBMI: Urban Employee Basic Medical Insurance; CMI: Commercial Medical Insurance

\section{Acknowledgements}

The authors sincerely thank all participants from the local health department and the center for disease control and prevention of Taizhou city of Zhejiang province, China. It is appreciated for the editor and anonymous reviewers for all the suggestions and valuable comments.

\section{Authors' contributions}

Zhigang Guo, Xiaodong Guan and Luwen Shi proposed the study, and participated in the design, data collection and analysis and drafting the manuscript. Liguang Zheng, Mengyuan $\mathrm{Fu}$, Huangqianyu $\mathrm{Li}$ and Lin Bai participated in data collection and analysis, and provided comments on the manuscript. All authors read and approved the final manuscript.

\section{Funding}

This study was supported by the National Natural Science Foundation of China (71774005) and Beijing Natural Science Foundation (9204031). The Foundations had no role in the study design, data collection, data analysis and interpretation, writing of the manuscript, and the decision to publication.

\section{Availability of data and materials}

The data used in the study are mainly the electronic health records and not public, belong to the health department of Taizhou city of Zhejiang province, which contain personal information of patients. Other researchers may need to obtain permission from health department of Taizhou city to access to the data. 


\section{Declarations}

\section{Ethics approval and consent to participate}

Data of this study was from the electronic health records of Taizhou city of China and was retrospective without direct contact with human subjects, by permission from the local health department. Before we received the data, all information were anonymized and de-identified by the privacy protection process. Ethical approval for this study was obtained from the Peking University Institutional Review Board (IRB00001052-18027-Exemption). All the authors confirm that methods of the study were carried out in accordance with relevant guidelines and regulations.

\section{Consent for publication}

Not applicable.

\section{Competing interests}

The authors declare that they have no conflict interest.

\section{Authors details}

${ }^{1}$ Department of Pharmacy, Peking University School and Hospital of Stomatology, Beijing 100081, China. ${ }^{2}$ International Research Center for Medicinal Administration, Peking University, Beijing 100191, China. ${ }^{3}$ School of Pharmaceutical Sciences, Peking University, Beijing 100191, China.

\section{References}

1. Kolasa K, Kowalczyk M. Does cost sharing do more harm or more good? - a system atic literature review. BMC Public Health. 2016; 16: 992. https://doi.org/10.1186/s1288 9-016-3624-6.

2. Fu X Z, Wang L K, Sun C Q, et al. Inequity in inpatient services utilization: a longi tudinal comparative analysis of middle-aged and elderly patients with the chronic noncommunicable diseases in China. Int J Equity Health. 2020; 19(1):6. https://doi.org/10. 1186/s12939-019-1117-9.

3. Pinto I, Lima M G, Pantuzza L, et al. Free access to medicines among older adults $\mathrm{i}$ n primary care: a cross-sectional study. Sao Paulo Med J. 2020; 138(3):235-243. https: //doi.org/10.1590/1516-3180.2019.0541.R1.19022020.

4. Wang Y, Zhu Y, Shi H, et al. The Effect of the Full Coverage of Essential Medicine s Policy on Utilization and Accessibility of Primary Healthcare Service for Rural Seni ors: A Time Series Study in Qidong, China. Int J Environ Res Public Health. 2019; 16(22): 4316. https://doi.org/10.3390/ijerph16224316.

5. Ross-Degnan D, Wallace J, Zhang F, et al. Reduced Cost-sharing for Preventive Drug 
s Preferentially Benefits Low-income Patients with Diabetes in High Deductible Health Plans with Health Savings Accounts. Med Care. 2020; 58 Suppl 6 Suppl 1: S4-S13. https://doi.org/10.1097/MLR.0000000000001295.

6. Zheng N T, Haber S, Hoover S, et al. Access to Care for Medicare-Medicaid Dually Eligible Beneficiaries: The Role of State Medicaid Payment Policies. Health Serv Re s. 2017; 52(6):2219-2236. https://doi.org/10.1111/1475-6773.12591.

7. Laba $\mathrm{T}$ L, Cheng L, Worthington $\mathrm{H} \mathrm{C}$, et al. What happens to drug use and expendi ture when cost sharing is completely removed? Evidence from a Canadian provincial public drug plan. Health Policy. 2020; 124(9):977-983. https://doi.org/10.1016/j.healthpo $\underline{1.2020 .05 .001}$.

8. Emmerick I, Campos M R, Da S R, et al. Hypertension and diabetes treatment afford ability and government expenditures following changes in patient cost sharing in the " Farmacia popular" program in Brazil: an interrupted time series study. BMC Public $\mathrm{H}$ ealth. 2020; 20(1):24. https://doi.org/10.1186/s12889-019-8095-0.

9. Puig-Junoy J, Garcia-Gomez P, Casado-Marin D. Free Medicines Thanks to Retiremen t: Impact of Coinsurance Exemption on Pharmaceutical Expenditures and Hospitalizatio n Offsets in a national health service. Health Econ. 2016; 25(6):750-767. https://doi.or $\mathrm{g} / 10.1002 / \mathrm{hec} .3182$.

10. Gonzalez L B, Librero J, Garcia-Sempere A, et al. Effect of cost sharing on adherenc e to evidence-based medications in patients with acute coronary syndrome. Heart. 201 7; 103(14):1082-1088. https://doi.org/10.1136/heartjnl-2016-310610.

11. Garchitorena A, Miller A C, Cordier L F, et al. In Madagascar, Use Of Health Care Services Increased When Fees Were Removed: Lessons For Universal Health Coverag e. Health Aff. 2017; 36(8):1443-1451. https://doi.org/10.1377/hlthaff.2016.1419.

12. Bose M, Dutta A. Health financing strategies to reduce out-of-pocket burden in India: a comparative study of three states. BMC Health Serv Res. 2018; 18(1):830. https:// doi.org/10.1186/s12913-018-3633-5.

13. Yaogo M. Free versus subsidised healthcare: options for fee exemptions, access to car e for vulnerable groups and effects on the health system in Burkina Faso. Health Res Policy Syst. 2017; 15(Suppl 1):58. https://doi.org/10.1186/s12961-017-0210-z.

14. Gong W, Zhang $\mathrm{C}, \mathrm{Xu} \mathrm{D} \mathrm{R}$, et al. The association between a free medicine program and functioning in people with schizophrenia: a cross-sectional study in Liuyang, Chi na. PeerJ. 2020; 8: e8929. https://doi.org/10.7717/peerj.8929.

15. Yu B, Zhang $\mathrm{X}$, Wang G. Full coverage for hypertension drugs in rural communities in China. Am J Manag Care. 2013; 19(1): e22-e29. https://www.ncbi.nlm.nih.gov/pmc/ articles/PMC4538950/.

16. Chen C, Pan J. The effect of the health poverty alleviation project on financial risk $p$ rotection for rural residents: evidence from Chishui City, China. Int J Equity Health 2019; 18(1):79. https://doi.org/10.1186/s12939-019-0982-6.

17. Lai S, Lu L, Zhou Z, et al. The effects of family physician-contracted service on hea lth-related quality of life and equity in health in China. Int J Equity Health. 2021; 20 (1):15. https://doi.org/10.1186/s12939-020-01348-4.

18. Li X, Li Z, Liu C, et al. Evaluation of the three-in-one team-based care model on hi erarchical diagnosis and treatment patterns among patients with diabetes: a retrospectiv 
e cohort study using Xiamen's regional electronic health records. BMC Health Serv R es. 2017; 17(1):779. https://doi.org/10.1186/s12913-017-2705-2.

19. Choudhry N K, Avorn J, Glynn R J, et al. Full coverage for preventive medications after myocardial infarction. N Engl J Med. 2011; 365(22):2088-2097. https://www.nejm. org/doi/full/10.1056/NEJMsa1107913.

20. Ito K, Avorn J, Shrank W H, et al. Long-term cost-effectiveness of providing full co verage for preventive medications after myocardial infarction. Circ Cardiovasc Qual O utcomes. 2015; 8(3):252-259. https://doi.org/10.1161/CIRCOUTCOMES.114.001330.

21. Taizhou Bureau of Statistics, Taizhou Investigation Team of National Bureau of Statist ics. Taizhou Statistical Year book (2017). China Statistics Press: Beijing, China. 2017. Available from: http://tjj.zjtz.gov.cn/art/2017/11/24/art_1229020475_42753763.html.

22. Marsicano E O, Fernandes N S, Colugnati F A, et al. Multilevel Correlates of Non-A dherence in Kidney Transplant Patients Benefitting from Full Cost Coverage for Immu nosuppressives: A Cross-Sectional Study. PLoS One. 2015; 10(11): e138869. https://doi. org/10.1371/journal.pone.0138869.

23. Sipos M, Farcas A, Prodan N, et al. Relationship between beliefs about medicines an $\mathrm{d}$ adherence in elderly patients with cardiovascular and respiratory diseases: A cross-se ctional study in Romania. Patient Educ Couns. 2021; 104(4):911-918. https://doi.org/10. 1016/j.pec.2020.09.001.

24. Cathbert T. Affordability effect of diabetic medicine on Patient's treatment adherence c ase study: Itojo Hospital in Ntungamo District. Diabetes Metab Syndr. 2019; 13(3):20 25-2031. https://doi.org/10.1016/j.dsx.2019.04.029.

25. Zhao Y, Zhou Z, Fan X, et al. Comparison of inequity in health-related quality of lif e among unemployed and employed individuals in China. BMC Public Health. 2021; 21(1):52. https://doi.org/10.1186/s12889-020-10038-3.

26. Pulok M H, Chirwa G C, Novignon J, et al. Levels of and changes in socioeconomic inequality in delivery care service: A decomposition analysis using Bangladesh Demo graphic Health Surveys. PLoS One. 2020; 15 (11):e242325. https://doi.org/10.1371/jour nal.pone. 0242325 .

27. Choudhry N K, Bykov K, Shrank W H, et al. Eliminating medication copayments red uces disparities in cardiovascular care. Health Aff. 2014; 33(5):863-870. https://doi.org/ 10.1377/hlthaff.2013.0654.

28. Cole M B, Ellison J E, Trivedi A N. Association Between High-Deductible Health Pl ans and Disparities in Access to Care Among Cancer Survivors. JAMA Netw Open. 2020; 3(6): e208965. https://doi.org/10.1001/jamanetworkopen.2020.8965.

29. Sunny A A, Iyer R S, Kumaran S G, et al. Affordability, availability and tolerability of anti-seizure medications are better predictors of adherence than beliefs: Changing $p$ aradigms from a low resource setting. Seizure. 2020; 83: 208-215. https://doi.org/10.10 16/j.seizure.2020.11.003.

30. Riley I L, Jackson B, Crabtree D, et al. A Scoping Review of International Barriers t o Asthma Medication Adherence Mapped to the Theoretical Domains Framework. J A llergy Clin Immunol Pract. 2021; 9(1):410-418. https://doi.org/10.1016/j.jaip.2020.08.021

31. Tavares N U, Luiza V L, Oliveira M A, et al. Free access to medicines for the treat ment of chronic diseases in Brazil. Rev Saude Publica. 2016; 50(suppl 2): 7s. https:// 
doi.org/10.1590/S1518-8787.2016050006118.

32. Emmerick I, Campos M R, Luiza V L, et al. Retrospective interrupted time series ex amining hypertension and diabetes medicines usage following changes in patient cost sharing in the 'Farmacia Popular' programme in Brazil. BMJ Open. 2017; 7(11): e173 08. http://dx.doi.org/10.1136/bmjopen-2017-017308.

33. Zombre D, De Allegri M, Ridde V. Immediate and sustained effects of user fee exem ption on healthcare utilization among children under five in Burkina Faso: A controlle d interrupted time-series analysis. Soc Sci Med. 2017; 179:27-35. https://doi.org/10.101 6/j.socscimed.2017.02.027.

34. Varas-Doval R, Gastelurrutia M A, Benrimoj S I, et al. Clinical impact of a pharmaci st-led medication review with follow up for aged polypharmacy patients: A cluster ran domized controlled trial. Pharm Pract (Granada). 2020; 18(4):2133. https://doi.org/10.18 549/PharmPract.2020.4.2133.

35. Zhou Z H, Wu Y F, Yan Y, et al. Persistence with medical treatment for Wilson dise ase in China based on a single center's survey research. Brain Behav. 2021; e2168. ht tps://doi.org/10.1002/brb3.2168.

36. Fosse-Edorh S, Fagot-Campagna A, Detournay B, et al. Impact of socio-economic pos ition on health and quality of care in adults with Type 2 diabetes in France: the Entr ed 2007 study. Diabet Med. 2015; 32(11):1438-1444. https://doi.org/10.1111/dme.12783.

37. Li X. Association of age and blood pressure among 3.3 million adults: insights from China PEACE million persons project. J Hypertens. 2021; 39(6):1143-1154. https://doi. org/10.1097/HJH.0000000000002793.

38. Li C, Chen K, Cornelius V, et al. Applicability and cost-effectiveness of the Systolic Blood Pressure Intervention Trial (SPRINT) in the Chinese population: A cost-effectiv eness modeling study. PLoS Med. 2021; 18(3): e1003515. https://doi.org/10.1371/journa 1.pmed.1003515.

39. Xia M, Liu K, Feng J, et al. Prevalence and Risk Factors of Type 2 Diabetes and Pr ediabetes Among 53,288 Middle-Aged and Elderly Adults in China: A Cross-Sectional Study. Diabetes Metab Syndr Obes. 2021; 14:1975-1985. https://doi.org/10.2147/DMS $\underline{\text { O.S305919. }}$ 


\section{Supplementary Files}

This is a list of supplementary files associated with this preprint. Click to download.

- 20210804additionalfiles.docx 